\title{
DIAGNÓSTICO E PLANEJAMENTO DE AÇÕES DE INTERVENÇÕES PARA MELHORIA DE AMBIENTE DE TRABALHO: UMA ABORDAGEM FABRIL
}

\author{
Adriano Pereira da Silva (UFBA) pereiras.adriano@gmail.com \\ Francisco Gaudêncio Mendonça Freires (UFBA) gaudenciof@yahoo.com
}

\begin{abstract}
Resumo
O presente artigo busca apresentar um estudo sistematizado, que consiste em identificar e analisar o nível de importância da psicologia organizacional de acordo com a percepção dos funcionários industriais de uma empresa localizada no Complexo Ford, cuja pesquisa são as instalações de uma empresa automobilística em Camaçari. Internamente a empresa localiza-se na área da montagem final da montadora, na qual metodologias definidas, pesquisa de procedimentos do trabalho, pressupõe-se uma utilização das ferramentas e instruções de documentos técnicos da área da psicologia, conciliada à verificação da concepção dos funcionários referente ao ambiente organizacional. Assim, observou-se um ambiente altamente propício para as boas práticas das atividades a serem desenvolvidas, perpassando pelos líderes e pares em qual estão alocados.
\end{abstract}

Palavras-Chaves: Ambiente organizacional. Estudo sistematizado. Percepção dos funcionários. Psicologia organizacional.

\section{Introdução}

A psicologia é a ciência do comportamento humano (e não humano), da cognição, da emoção e da motivação e pode ser subdividida em muitas diferentes especializações, algumas das quais se ocupam principalmente da ciência psicológica (psicologia experimental) e outras se concentram tanto na ciência psicológica quanto na aplicação dessa ciência a problemas do mundo real fora do âmbito da pesquisa. A psicologia organizacional (juntamente com a psicologia clínica) se enquadra na segunda categoria, por se ocupar tanto da ciência psicológica quanto de sua aplicação.

O campo da psicologia organizacional contém duas principais divisões: o lado industrial (ou do pessoal) e o lado organizacional. Apesar de os conteúdos das duas principais divisões se sobreporem e não poderem ser facilmente separados, cada uma delas é proveniente de tradições diferentes na história dessa área de conhecimento (SPECTOR, 2012). Por conseguinte, costuma-se dividir a atuação da psicologia organizacional em profissionais voltados à prática e profissionais voltados à pesquisa científica. As atividades práticas envolvem a utilização de princípios psicológicos para solucionar problemas do mundo real, como estresse excessivo no trabalho ou desempenho insatisfatório. Assim, os psicólogos 
organizacionais muitas vezes trabalham para governos (municipais, regionais, estaduais ou federais), as forças armadas (normalmente como especialistas civis) e empresas privadas e em cada uma dessas diferentes áreas de atuação prática podem realizar os mesmos tipos de atividades (ZANELLI; BORGES-ANDRADE; BASTOS, 2014).

Diante este cenário, a questão problema que direciona este trabalho é: Qual nível de importância da psicologia organizacional de acordo com a percepção dos funcionários industriais de uma empresa localizada no Complexo Ford? Nesse sentido, o objetivo geral é realizar uma pesquisa verificar o nível de importância da psicologia organizacional de acordo com a percepção dos funcionários industriais de uma empresa localizada no Complexo Ford. Paralelo a isso, os objetivos específicos são: elaborar um questionário envolvendo aspectos de satisfação dos funcionários; realizar uma pesquisa de opinião com os funcionários selecionados; analisar os dados coletados com a pesquisa supracitada.

Desta forma, o presente artigo busca apresentar um estudo sistematizado, que consiste em identificar e analisar o nível de importância da psicologia organizacional de acordo com a percepção dos funcionários industriais de uma empresa localizada no Complexo Ford. Assim, quais possíveis sugestões de melhorias poderão ser aplicadas para uma melhoria dentro do processo industrial.

Nesta seção apresenta o tema pesquisado, assim como sua importância, objetivos, metodologia e a estruturação do trabalho. Logo depois, identifica-se o referencial teórico. A seção seguinte aborda a metodologia. Por fim, observa-se a análise e discussão dos dados; considerações finais e referências respectivamente.

\section{Revisão teórica}

A psicologia organizacional é uma invenção do século XX, com raízes no fim do século XIX e existe praticamente desde o início do campo da psicologia. Os primeiros psicólogos a se envolverem na psicologia organizacional foram psicólogos experimentais interessados na aplicação dos novos princípios da psicologia a problemas nas organizações (BOCK; FURTADO; TEIXEIRA, 2019). Na realidade, ao observarmos sua concepção de organização como um todo, observa-se a importância da subjetividade. A direção e os planejadores - para 
produzir e impor as diretrizes da empresa, sua política, sua estratégia e seus objetivos necessitam pensar, decidir, planejar, avaliar, assim por diante.

A medida que o campo se desenvolveu, na primeira metade do século, ele se expandiu para as áreas atuais. Uma importante influência no campo da psicologia organizacional foi a obra de Frederick Winslow Taylor, um engenheiro que passou a carreira estudando a produtividade de funcionários no final do século XIX e início do século XX. Taylor desenvolveu o que chamou de administração científica, como uma abordagem para gerir trabalhadores de manufatura em fábricas (JOHANN, 2017). Por conseguinte, a Primeira Guerra Mundial marcou o início da utilização da psicologia organizacional para ajudar nos esforços de guerra tanto no Reino Unido quanto nos Estados Unidos. Durante as décadas entre as duas guerras mundiais, a psicologia organizacional se expandiu, formando a maioria das áreas existentes atualmente. À medida que as organizações cresciam, elas começaram a contratar psicólogos organizacionais para lidar com seus crescentes problemas com os funcionários, em especial questões relevantes à produtividade nos Estados Unidos (PIKETTY, 2014).

Assim, a pesquisa é uma das principais atividades dos psicólogos organizacionais, podendo desenvolver novos métodos e procedimentos para atividades como seleção e treinamento de funcionários. Outras pesquisas se concentram em compreender algum fenômeno organizacional, como a causa de furtos por parte dos funcionários ou o efeito das atitudes no trabalho. As conclusões desses tipos de pesquisa são apresentadas em conferências dos profissionais da área e publicados em periódicos científicos (SPECTOR, 2012). Diante deste contexto, percebe-se um mundo globalizado, nas quais as empresas necessitam ser altamente competitivas para garantir sua continuidade e prosperidade. Nessa constante busca de aperfeiçoamento e evolução, tornou-se indispensável que as organizações direcionem sua atenção não exclusivamente para o desenvolvimento de seus produtos e comercialização de seus serviços, mas para seus trabalhadores, de forma que estes não sejam apenas considerados meios produtivos. Assim, as organizações compreenderam que as pessoas são um recurso importante nessa disputa por mercado, pois são portadoras de conhecimento e habilidades, elas são o grande diferencial das empresas (RIBEIRO, 2017).

No nível organizacional, leva-se em consideração, basicamente, a eficiência, trabalhando a racionalização da produção, principalmente, a partir da especialização. No aspecto ambiental, considera-se a habilidade e a disponibilidade de empregados e as expectativas sociais. Em relação à habilidade e à disponibilidade de empregados, deve-se analisar se os trabalhadores 
não estão sendo direcionados para cargos acima ou abaixo dos seus interesses profissionais. As expectativas sociais também devem ser analisadas de forma cautelosa. Assim, o nível comportamental é o mais sensível, pois se refere às necessidades humanas, aos modos de comportamentos individuais no ambiente de trabalho, que são de alta importância, tais como: autonomia do indivíduo para assumir responsabilidade pelo trabalho, variedade da tarefa - que reduz o tédio e a fadiga, identidade de tarefa, ou seja, sentir orgulho pelo resultado da tarefa; e retro informação, que possibilita ao trabalhador saber qual a repercussão do seu trabalho, com isso melhorando a motivação (BERNDT, 2019).

Nesse sentido, toma-se com cuidado a Qualidade de Vida no Trabalho para o funcionário, na qual tem sido uma preocupação constante da humanidade, desde as primeiras civilizações. A Qualidade de Vida no Trabalho faz parte das modificações pelas quais passam as relações de trabalho na sociedade contemporânea. Assim, é desenvolvida na área da saúde e, posteriormente, ampliando conhecimentos nas áreas de Psicologia, Sociologia e da Administração (BITTAR, 2017). Por essa razão, suas definições são diversas, com implicações éticas e políticas. Para tanto, a Qualidade de Vida se torna um assunto atraente, no entanto, cheio de contradições. De um lado, encontra-se maior conhecimento disponível sobretudo, pressa para o consumo e mais liberdade para escolher hábitos e estilo de vida. De outro lado, aparecem as consequências das contínuas e crescentes exigências de qualificações, que se mostram sempre insatisfatórias. Afinal "trata-se de uma competência organizacional, cuja capacidade de solução pressupõe: vontade, legitimidade e qualificação dos diversos níveis do poder, interesses e impactos" (LIMONGI-FRANÇA, 2010).

\section{Metodologia}

Para obtenção do objetivo proposto foi realizado inicialmente uma pesquisa bibliográfica exploratória através de livros, artigos científicos, trabalhos acadêmicos e documentos eletrônicos, seguida por uma análise qualitativa, sendo esta realizada a partir de um questionário de entrevista.

\subsection{Contextualização da abordagem}

Em dezembro de 1997 surge o Grupo Faurecia Automotive, uma multinacional francesa, fruto da união entre as empresas Faure Automotive e Ecia Automotive, fabricantes de sistemas 
automotivos nas modalidades de escapamentos, painel de instrumentos, bancos e módulos de portas para automóveis. O Grupo está entre os 8 maiores fornecedores do setor automobilístico: possui mais de 70.000 colaboradores, 190 unidades fabris, 28 centros de P\&D e está presente em 28 países.

O Sistema de Excelência Faurecia (FES) atende seus objetivos para proporcionar uma visão abrangente do modo como deve funcionar na sequência de implementação e do aperfeiçoamento contínuo dos seus processos essenciais, integrando ferramentais e técnicas concebidas para ajudar cada um dos colaboradores a progredir e a contribuir para o sucesso do grupo. Para o grupo, esta ferramenta é o principal valor para o cliente, pois é a essência para atingir com primazia as expectativas dos stakeholders. Ela se concentra em três pilares fundamentais: na qualidade de seus produtos, no cumprimento irrepreensível de seus prazos e na busca contínua pela redução dos custos. Assim, o grupo acredita que o sucesso somente é alcançado através da eficiência contínua, da inovação permanente e da globalização. Portanto, é fundamental estimular o comprometimento de seus colaboradores e fornecedores numa relação que assegure à Faurecia Automotive a essência de sua razão de ser.

Foi inaugurada em 2001 a primeira filial no Nordeste trabalha apenas com componentes da porta do carro. A fábrica localiza-se dentro de um Complexo Industrial Automotivo, junto com outras 27 empresas fornecedoras de peças ou componentes automotores. Os fornecedores ficam localizados internamente na linha de montagem, fornecendo produtos diretamente ao cliente. No Complexo Industrial, são fabricados dois modelos de veículos. Inicialmente, com uma faixa de produção em torno de 1.045 veículos por dia. A montadora trouxe à região uma grande transformação social, ambiental e conceitos inovadores de produção nunca vistos até então no Nordeste.

\subsection{Participantes}

O ambiente de pesquisa são as instalações de uma empresa automobilística localizada no Polo Petroquímico em Camaçari. Internamente a empresa localiza-se na área da montagem final da montadora, sendo que operadores, supervisores, engenheiros, técnico em segurança do trabalho, psicólogo e auditores da qualidade fazem parte do quadro funcional e representa relevância nas abordagens e desenvolvimento deste trabalho. 


\subsection{Coletas de dados}

Devido às metodologias definidas, pesquisa de procedimentos do trabalho, pressupõe-se uma utilização das ferramentas e instruções de documentos técnicos da área da psicologia, conciliada à verificação da concepção dos funcionários referente ao ambiente organizacional. A coleta de dados será realizada por meio de um formulário. A assimilação destas etapas proporciona o desenvolvimento da pesquisa, cujo dados serão coletados e organizados para análise.

\section{Análise e discussão dos dados}

Diante a análise de campo, a partir da entrevista com coordenador de pessoal da organização, identificamos o mapeamento dos principais aspectos relacionados a organização, na qual a imagem a seguir ilustra as características principais da organização em linhas gerais.

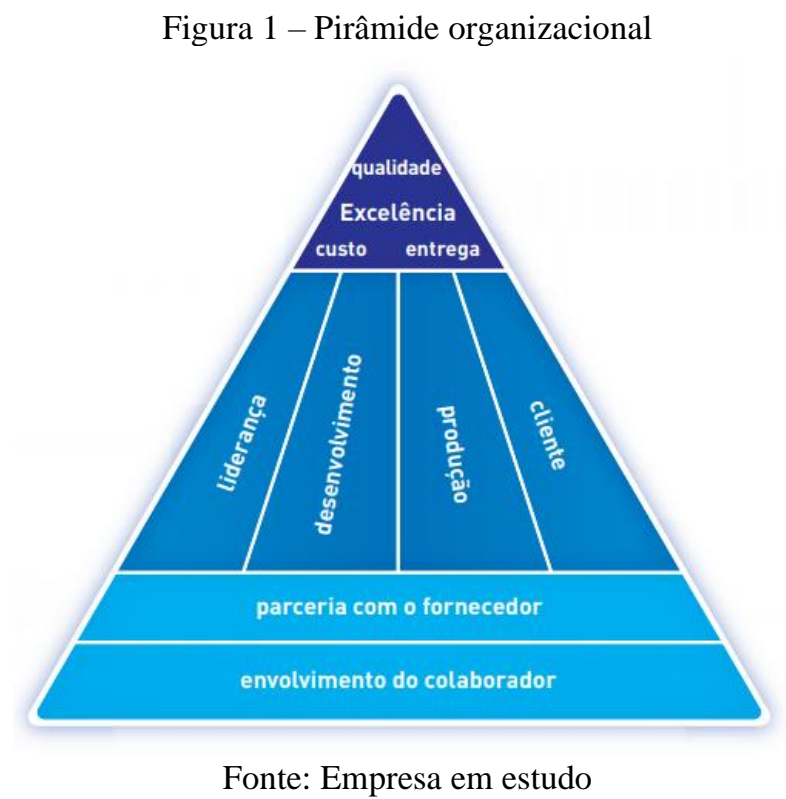

Dessa forma, entende-se que a Faurecia é comprometida em agregar valor aos clientes, colaboradores e acionistas, alcançando a excelência em Qualidade, Custo e Entrega. Para alcançar este objetivo, nós desenvolvemos o FES com o suporte de 4 pilares (Liderança, Desenvolvimento, Produção e Cliente), junto com as bases Parceria com o Fornecedor e Envolvimento do Colaborador. Por conseguinte, este sistema foi construído com base em práticas e princípios demonstrados e testados em todo o mundo. Os padrões são constantemente melhorados através de benchmarking e desenvolvimento de boas práticas. 
Utilizar metodologias e ferramentas padronizadas é a maneira Faurecia de desenvolver pessoas e fortalecer uma cultura em comum.

Os gerentes são a base do sistema. Seu papel é liderar pelo exemplo e treinar suas equipes. Todos colaboradores da Faurecia, usam do FES para contribuir com a melhoria contínua no dia-a-dia de trabalho. Ou seja, uma condição para o sucesso, visando a busca pela melhoria contínua com o envolvimento ativo de todos os colaboradores, em todos os níveis da empresa: gerencial, funções de suporte/apoio e operadores. Assim, a seguir estão dispostos os aspectos chave desenvolvidos organizacionalmente.

Figura 2 - Aspectos organizacionais

\begin{tabular}{|c|c|}
\hline Ferramentas / Metodologia & \\
\hline $\begin{array}{l}\text { > Validação da OHP conforme budget } \\
\text { > Painel Operacional do GAP } \\
\text { e indicadores adequados } \\
\text { > TOP5 diários (do GAP para } \\
\text { o Time de gestão) }\end{array}$ & \\
\hline $\begin{array}{l}\text { > Supervisor Dashboard e revisão } \\
\text { > Rotinas como pré-requisito para }\end{array}$ & $\begin{array}{l}\text { Indicadores } \\
\text { Chave de Performance (KPI) }\end{array}$ \\
\hline $\begin{array}{l}\text { > Desenvolvimento do papel } \\
\text { (dos GAP Líderes e Supervisores) }\end{array}$ & $\begin{array}{l}\text { > Relações GAP \& Supervisor } \\
\text { > Ideias de melhoria implementadas }\end{array}$ \\
\hline $\begin{array}{l}\text { > Polivalência (relacionado com } \\
\text { o Trabalho Padronizado) }\end{array}$ & $\begin{array}{l}\text { > Horas de treinamento } \\
>\text { Status do Guia de Desenvolvimento } \\
\text { do Supervisor (\%) }\end{array}$ \\
\hline $\begin{array}{l}\text { > Sistema de idéias de melhoria } \\
\text { e reconhecimento }\end{array}$ & > Taxa de absentismo mão de obra \\
\hline $\begin{array}{l}\text { > Processo de Transferência } \\
\text { de Tarefas }\end{array}$ & $>$ Mobilidade interna \\
\hline $\begin{array}{l}\text { > Plano de treinamento ligado } \\
\text { às prioridades operacionais }\end{array}$ & $\begin{array}{l}\text { > Rotatividade de pessoal } \\
\text { > Recrutamento interno }\end{array}$ \\
\hline
\end{tabular}

Fonte: Empresa em estudo

Mediante essa conjuntura, segue os gráficos que representam o nível de satisfação e insatisfação dos funcionários. 
Figura 3 - Nível de Satisfação

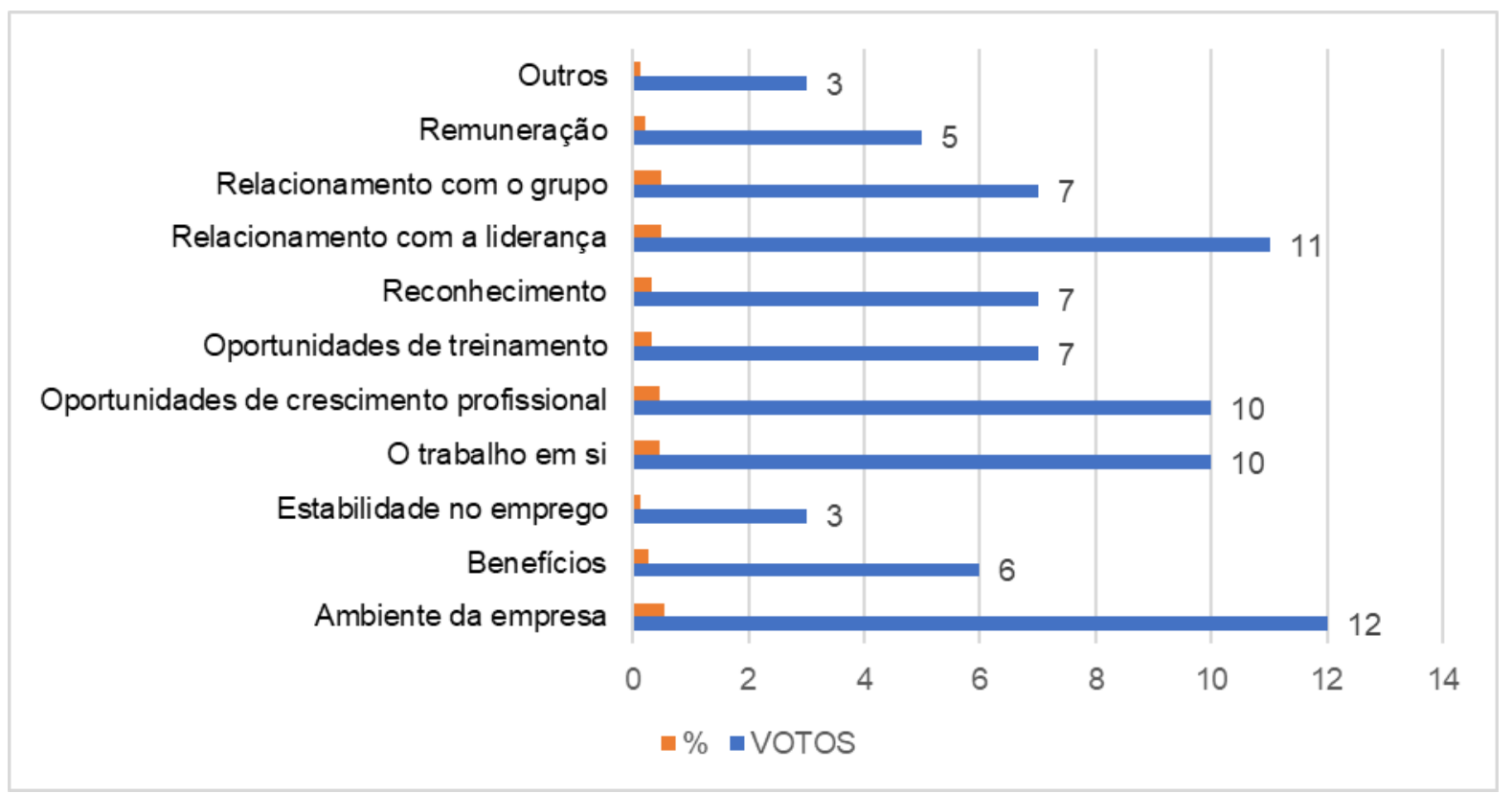

Fonte: Autoria própria

Figura 4 - Nível de Insatisfação

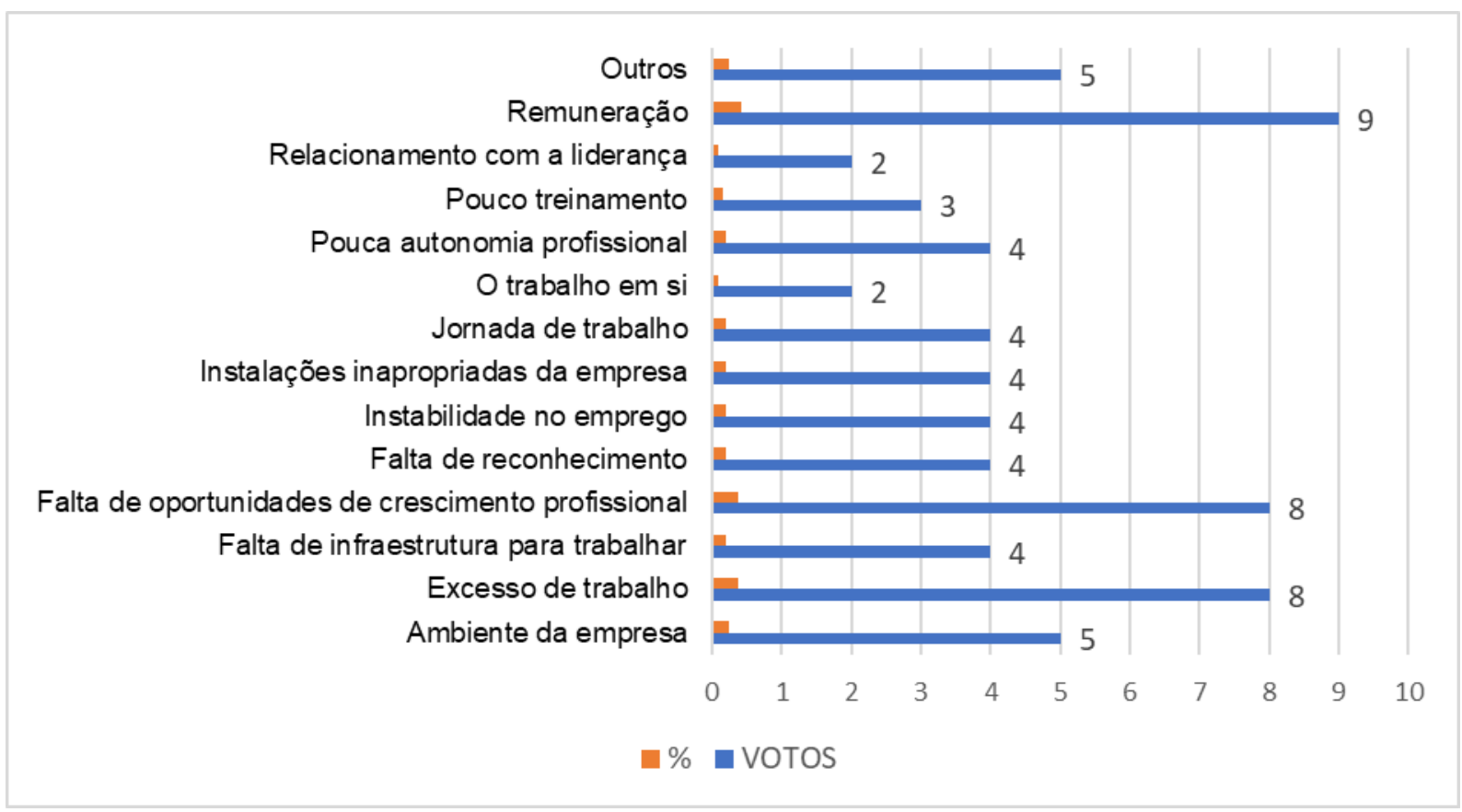

Fonte: Autoria própria

A partir disso, nota-se uma tendência dos resultados obtidos em ambos os caso, cuja a satisfação no trabalho está diretamente relacionada com o ambiente da empresa, contrastando como o que popularmente é difundido que o principal fator está relacionado com remuneração ou benefícios, entretanto, este último aparece em segundo lugar, bem próximo do top, 
juntamente com reconhecimento (este, por sua vez, condiz com o ambiente/pessoas que atuam conjuntamente). Vale ressaltar que o menos avaliado corresponde diretamente a estabilidade do emprego.

Não obstante, no tocante da insatisfação, observa-se que o índice de maior valor corresponde a remuneração, contrastando com os dados mencionados anteriormente. Assim, entende-se que ainda é um fator que impacta nas condições/concepção do trabalhador dentro da organização. Em paralelo, os dados de menores valores estão representados no trabalho em si (ou seja, as tarefas realizadas) e relacionamento com a liderança (demonstrando um ambiente cordial).

\section{Considerações finais}

Diante dos dados coletados, observa-se que a Faurecia compromete-se a criar e manter um ambiente profissional que garanta a igualdade de oportunidades e proíba qualquer forma de discriminação entre os empregados, quaisquer que sejam a idade, a etnia, o sexo, a cor, a nacionalidade, a religião, o estado de saúde ou a deficiência, a orientação sexual, as opiniões políticas, filosóficas ou sindicais ou qualquer outro critério estipulado pela lei aplicável. Cabe a cada colaborador manter o seu ambiente de trabalho isento de qualquer forma de discriminação, hostilidade ou assédio, incluindo o assédio sexual. Além disso, compromete-se a implementar políticas e métodos de prevenção ativa dos riscos que possam afetar a saúde e a segurança dos empregados, a controlar em permanência a sua correta aplicação e a medir a sua eficácia. Ademais, todos os subcontratados que trabalham nas instalações da empresa devem cumprir as mesmas políticas em matéria de saúde e segurança.

Desta forma, esclarece os resultados da pesquisa, na qual o ambiente oferecido é altamente propício para as boas práticas das atividades a serem desenvolvidas, perpassando pelos líderes e pares em qual estão alocados. Vale mencionar que a remuneração ainda é o principal fator de coincide na insatisfação dos funcionários, mesmo não sendo o principal dentre dos os dados avaliados, porém, criando uma política de cargos e salários, promoveria uma diminuição da insatisfação geral. 


\section{REFERÊNCIAS}

BERNDT, Dennison Nunes. Recursos Humanos: Como A Qualidade De Vida No Trabalho Pode Ser Uma Ferramenta Motivacional. Unisanta Business And Management, V. 2, N. 1, P. 111-129, 2019.

BITTAR, Carlos Alberto. Os direitos da personalidade. Editora Saraiva, 2017.

BOCK, Ana Mercês Bahia; FURTADO, Odair; TEIXEIRA, Maria de Lourdes Trassi. Psicologia. Saraiva Educação SA, 2019.

JOHANN, Silvio Luiz. Comportamento organizacional. Editora Saraiva, 2017.

LIMONGI-FRANÇA, Ana Cristina. Qualidade de vida no Trabalho - QVT: conceitos e práticas nas empresas da sociedade pós-industrial. 2. ed. São Paulo: Atlas, 2010.

NEVES, Roberta Braga; PEREIRA, Valdecy and COSTA, Helder Gomes. Auxílio multicritério à decisão aplicado ao planejamento e gestão na indústria de petróleo e gás. Produção. 2015, vol.25, n.1, pp.43-53. Epub Sep 03, 2013.

PIKETTY, Thomas. O capital no século XXI. Editora Intrínseca, 2014.

RIBEIRO, Antônio de Lima. Teorias da administração. Editora Saraiva, 2017.

SPECTOR, Paul E. Psicologia nas Organizações. 4. São Paulo: Saraiva, 2012.

ZANELLI, José Carlos; BORGES-ANDRADE, Jairo Eduardo; BASTOS, Antonio Virgílio Bittencourt. Psicologia, Organizações e Trabalho no Brasil-2. AMGH Editora, 2014. 
ANEXO

\section{PESQUISA DE OPINIÃO}

Pode marcar mais do que uma opção

\section{Marque quais fatores trazem mais SATISFAÇÃO no seu trabalho}

$\circ\ulcorner$ Ambiente da empresa

- ᄃ Benefícios

$\circ \Gamma$ Estabilidade no emprego

$\circ \Gamma$ O trabalho em si

- $\square$ Oportunidades de crescimento profissional

$\circ\ulcorner$ Oportunidades de treinamento

○ Г Reconhecimento

- $\sqsubset$ Relacionamento com a liderança

$\circ \Gamma$ Relacionamento com o grupo

$\circ \Gamma$ Remuneração

$\circ \Gamma$ Outros

Marque quais fatores trazem mais INSATISFAÇÃO no seu trabalho

- ᄃ Ambiente da empresa

- $\square$ Excesso de trabalho

$\circ \sqsubset$ Falta de infraestrutura para trabalhar

$\circ \quad$ Falta de oportunidades de crescimento profissional

$\circ\ulcorner$ Falta de reconhecimento

$\circ \Gamma$ Instabilidade no emprego

- Г Instalações inapropriadas da empresa

$\circ\ulcorner$ Jornada de trabalho

○ $\ulcorner$ O trabalho em si

- $\square$ Pouca autonomia profissional

- ᄃ Pouco treinamento

$\circ\ulcorner$ Relacionamento com a liderança

○ Г Remuneração

$\circ \Gamma$ Outros 